J. Egypt. Soc. Parasitol. (JESP), 44(3), 2014: 639 - 652

\title{
ZOONOTIC MYIASIS IN EGYPT: WITH REFERENCE TO NOSOCOMIAL OR HOSPITAL-ACQUIRED MYIASIS
}

\author{
By \\ TOSSON A. MORSY \\ Department of Parasitology, Faculty of Medicine, Ain Shams University, \\ Cairo 11566, Egypt \\ Abstract
}

The most important insects from medical point of view are the blood suckers or the insectborne diseases. Still others, almost non-blood suckers, but may attack man and animal to deposit their eggs or larvae of myiasis producing flies in skin, nose, eye, lung, ear, anus, vagina, and oral cavity as well as accidental gastrointestinal ones causing pathogenic condition known as myiasis causing different pathogenic conditions. Nosocomial myiasis must be noted carefully, especially in case of hospitalized patients. Myiasis is a real welfare problem and many myiasis producers are zoonotic parasites. The nosocomial myiasis illustrates an unusual problem that may confront those responsible for infection control programs. However, still little is known about such an important subject in Egypt. This review would assist in designing appropriate prevention protocols and devising suitable control strategies to overcome zoonotic and nosocomial myiasis and alleviate the economic losses.

Key words: Egypt, Zoonotic myiasis, Nosocomial myiasis

\section{Introduction}

Myiasis (/'mai.əsis/ or /mar'ar.əsis/) is the infestation of the body of a live human being or other vertebrate by fly larvae that feed on its tissue. When the attack is directed against dead or necrotic tissue, the condition is not necessarily harmful and the effects may be of value as maggot therapy. Hope (1840) coined the term myiasis to refer to diseases resulting from dipterous larvae as opposed to those caused by other insect larvae (the term for this was scholechiasis), and described several cases of myiasis from Jamaica caused by unknown larvae, one of which resulted in death, Colloquialisms for myiasis include fly-strike, blowfly strike, and the victim or the tissue may be described as flyblown (Show, 1974). Name of the condition was derived from the ancient Greek $\mu v i \tilde{\alpha}$ (myia), meaning "fly". Myiasis, a term introduced by William Hope in 1840, referred to the invasion of tissues and organs of animals and human wounds and certain body cavities by the dipteran larvae, which manifests as subcutaneous furunculoid or boillike lesions (Kathleen, 2005).

Many human skin diseases in ancient times, although different in their cutaneous manifestations and etiologies, were grouped together under the catch-all term, "leprosy."
Nowadays, the skin lesions have many causes, including the infections by all classes of organisms (viruses, bacteria, fungi, helminthes and protozoa), arthropod bites and infestations, allergic and hypersensitivity reactions (Morsy, 2012a). Such was not the case for the presence of fly larvae (maggots) in tissues or wounds of man or domestic animals. The presence of live maggots in a wound or their escape from a living being's body is a condition that could not be confused with any other syndrome. As early as $\mathbf{5 2 0}$ B.C., Herodotus the "Father of History," described a case of facultative myiasis in a woman. "No sooner had she returned to Egypt, than she died a horrible death, her body seething with maggots while she was still alive." The Holy Bible alludes several times to maggots infesting human flesh. In Job7:5, the afflicted Job states "My flesh is clothed with maggots and clouds of dust, my skin rotted and fouled a fresh" In Acts 12: 23, it is recorded that King Herod died 5 days after being smitten with gangrene, during that time maggots bred in gangrenous mass. But, historical descriptions are not restricted to man. In the Hortus-Sanitatis published in Antwerp, Belgium in 1521, there are woodcuts that imply that the authors were aware of life cycle of flies that would swarm on 
maggot-infested meat and would attack a dead or dying animal (Greenberg, 1973).

Myiasis varies widely in the forms it takes and its effects on the victims. Such variations depend largely on the fly species and where the larvae are located. Some flies lay eggs in open wounds, other larvae may invade unbroken skin or enter the body through the nose, ears, oral cavity and/or vagina. In Patton's categorization (1922), there are two main groups of myiasiscausing species: the specific parasites, which must develop on live hosts; and the semispecific parasites, which usually develop on decaying organic matter, such as carrion, faeces and rotting vegetation, but may also deposit their eggs or larvae on live hosts. Zumpt (1965) termed the specific parasites obligatory and the semi-specific parasites facultative. Diagnosis of myiasis depends on the demonstration of larvae on the host's tissues or organs. Correct identification of the larvae is important for the initiation of appropriate treatment and establishment of preventive measures. The risk factors that potentially cause myiasis are the exposure of ulcers and hemorrhoids, bacterial infection of wounds or natural cavities, poor personal hygiene, alcohol-related behaviors such as lack of sensitivity and sleeping outdoors, lesions resulting from itching in patients with pediculosis, and extreme lack of personal hygiene (Morsy, 2012b).

Nosocomial myiasis refers to myiasis in a hospital setting. It is quite frequent, as patients with open wounds or sores can be infested if flies are present. To prevent nosocomial myiasis, hospital rooms must be kept free of flies (Bilal et al, 2012). Wound myiasis occurs when fly larvae infest open wounds. It has been a serious complication of war wounds in tropical areas, and is sometimes seen in neglected wounds in most parts of the world. Predisposing factors include poor socioeconomic conditions, extremes of age, mental retardation, psychiatric illness, alcoholism, diabetes, and vascular occlusive disease. Sukontason et al.
(2014) stated that the medical involvement of Sarcophaga dux larvae was not only myiasis-producing agent in humans and animals, but associated with human death investigations.

On the other hand, Al-Wahbi (2006) reported that the prevalence of diabetic foot ulcers in the Arab world in general was high, compared with Western Countries and that few studies illustrated the efficacy and associated healing mechanisms of local therapy of progenitor cells in a preclinical model of the diabetic ischaemic foot ulcer $(\mathrm{Gu}$ et al, 2007). El-Sharawy et al. (2012) in Egypt stated that diabetic patients with foot ulcers usually were manifested with high amputation and mortality rates and that treatment with the CD34+-enriched cells decreased wound size, accelerated epidermal healing and dramatically accelerated revascularization of wounds compared with the DC group. Assaad-Khalil et al. (2013) in Egypt stated that physicians in the Middle East and South Africa identified limitations relating to their patients as the main barrier to delivering care for diabetes, without giving high priority to issues relating to processes of care delivery. Further study would be needed to ascertain whether these findings reflect an unduly physician-centred view of their practice.

Abroad, nosocomial myiasis or hospital acquired myiasis was reported by many authors worldwide. The following are selected ones arranged according to year of publications. Soliman and Morsy (1976) in Saudi Arabia recommended myiasis in medicolegal practice Terra and de Siqueira (1980) in Portugal reported intra-oral myiasis. Mielke and Schlote (1980) in Germany reported hospital acquired myiasis. Jacobson et al. (1980) encountered two patients with hospital-acquired myiasis, a rarely reported nosocomial problem over three years. Both patients were elderly and had lengthy thoracic surgery in August in the same operating room. Larvae removed from the nares of one patient and from the chest incision of 
the other were Phaenicia serricata. There was no evidence of tissue destruction or invasion in either case. Investigation revealed several factors that contributed to the presence of flies in the operating room. After a presumed environmental access site was closed and insecticide spraying was augmented, no additional cases occurred.

Smith and Clevenger (1986) in USA retrieved sixty-five fly maggots from the nasal that immobile and debilitated patients are at risk to acquire myiasis. De Kaminsky (1993) in Honduras reported nosocomial myiasis caused by the screw larvae of Cochliomyia hominivorax. Josephson and Krajden (1993) in Canada found a number of fly maggots emerging from the nose and tracheostomy site of an 82-year-old woman who had been in a coma for two months in an acute care hospital in a large Canadian city. This case history indicated that the infestation was hospital-acquired and although undoubtedly an extremely rare occurrence, at least in Canada, points out the risk of myiasis in the unconscious, debilitated patient. Daniel et al. (1994) in Czech Republic reported a case of traumatic nosocomial myiasis caused by the green bottle fly $L$. sericata occurred in a patient hospitalized following a serious road traffic accident. The patient had suffered extensive polytrauma particularly in the facial area of the skull. A total of 50 larvae was discovered in the oral cavity, nose, paranasal sinuses and enucleated eye-socket. Projected timing indicated that the eggs were laid while the patient was hospitalized. The development of myiasis was facilitated by the mental and physical debility and dependency of the patient, numerous and deep facial necrotic wounds and a lengthy period of hot weather which led to prolonged open window ventilation of his room.

Minár et al. (1995) in Praha (Czechoslovakia) described a case of nosocomial myiasis of cavities caused by larvae of $L$. sericata in a patient hospitalized at the resuscitation unit after a motor car accident where he suffered fractures of the skull and other inju- cavity of an unconscious 64-year-old man who had been admitted 18 days earlier with diabetic hyperosmolar coma. These larvae were identified as Cochliomyia macellaria, an organism commonly associated with myiasis. The clinical time sequence indicates that this infection was acquired in the hospital. This incident provides further evidence

ries. On the fourth day, in the nasal and oral cavity of the patient were $1^{\text {st }}$ and $2^{\text {nd }}$ instars of larvae the insect. The ova were laid in hospital. L. sericata is the most frequent causal agent of tissue, cavity, ocular and urogenital human myiasis in Central Europe. They reported three nosocomial ones and concluded that myiases usually attack immobile, injured or severely ill people in summer. It is important to draw attention to the hazard of myiases under exceptional conditions.

Mielke (1997) Magdeburg, Germany reported that flies larvae invaded man that was referred to myiasis. He added that recorded the cases of nosocomial myiasis documented worldwide. Twenty-three cases of this hospital infection, which have occurred in a number of countries were found in the literature, and analyzed.

Amitay et al. (1998) in Israel reported nosocomial myiasis in an extremely premature infant caused by L. sericata. Joo and Kim (2001) In Korea reported a case of nosocomial cutaneous myiasis caused by $L$. sericata (Meigen, 1826) in a 77-year-old male was found. The patient had been receiving partial maxillectomy due to the malignant tumor on premaxilla. This is the first verified case involving $L$. sericata in Taegu. Greco et al. (2001) in Brazil reported diabetic ulcer infested with myiasis was superimposed with Clostridium tetani.

Otranto et al. (2004) reported two species; Rhinoestrus purpureus (Brauer) and R. usbekistanicus Gan that caused nasal myiasis in horses, donkeys and zebras, and that in the past 15 years myiasis caused by $R$. pur- 
pureus was reported in Egypt and by $R$. usbekistanicus in Senegal and Niger, both in horses and in donkeys.

Couppié et al. (2005) in French Guiana reported a bed-ridden patient with dementia who developed right nasal myiasis during his stay at Cayenne Hospital. Progression was favorable, but the nasal pyramid was partially destroyed. In zones where this fly is endemic, particular attention should be given to hospitalized patients with wounds and consciousness problems. Chan et al. (2005) in Hong Kong, China reported eight cases of human myiasis, who were nursing home residents with an over age of 81.8 years. Seven patients were bedridden with advanced dementia. Four patients had pre-existing wounds. Five had poor oral hygiene and four of those were on tube feeding. All of the five patients with poor oral hygiene suffered from oral myiasis. Two patients had vaginal infestations and one had wound myiasis in his diabetic foot ulcer. Seven cases were infested by $C$. bezziana, an obligatory parasite that requires living mammalian tissue for its larval develmaining case. Patients were managed with manual removal of larvae and irrigation of the site of infestation with saline. All infestations were nosocomial, being acquired in nursing homes. They concluded that the old and debilitated patients should be made aware of the need for better oral care, especially for those on tube feeding. The use of window screens in nursing homes should be encouraged to reduce the chance of flies entering the vicinity of these patients. Electrocutes could also be mounted indoors to kill flies that do enter.

Rubio et al. (2006) in Spain reported hospital acquired myiasis over tumor lesions. Szakacs et al. (2007) in Ottawa Hospital reported nosocomial myiasis in the intensive care unit. Hemmings et al. (2007) in western Jamaica stated that zoonotic myiasis has been remained a public health problem without significant decrease in cases admitted to the Cornwall Regional Hospital since 1999, and become a Class 1 notifiable dis- ease to the Ministries of Health and Agriculture. Verettas et al. (2008) in Greece reported hospital acquired myiasis on external fixation pin sites in diabetic patients.

Sesterhenn et al. (2009) in Germany reported nosocomial myiasis in malignant wounds in the head and neck. Kim et al. (2009) Korea discovered 5 larvae inside the nose of a 76-year-old female, who was in a coma due to rupture of an aortic aneurysm. Surgery on the day of admission, and $L$. sericata larvae were found 4 days later.

Mowlavi et al. (2011) reported a fatal nosocomial myiasis caused by L. sericata. Nazni et al. (2011) in Malaysia reported a 73year-old Chinese man admitted to the Accident and Emergency Premorbid Ward of a local hospital, with shortness of breath with cough and was in a semi-conscious state. $\mathrm{He}$ was later admitted to an intensive care unit (ICU) of the hospital. Six days after admission 5-6 maggots were recovered from the nasal cavity. The maggots were identified as the third-instar larvae of Lucilia cuprina Wiedmann based on the morphological characteristics. This patient was classified as having nosocomial myiasis. The presence of the third instar larvae indicated that the infestation was not more than three to four days, an adult sarcophagid identified as the Parasarcophaga ruficornis. Maleki Ravasan et al. (2012) reported nosocomial nasal cavity of a 5.5-year-old Iranian girl. Quesada-Lobo et al. (2012) in Costa Rica reported a case of nosocomial myiasis due to L. cuprina. Sharma (2012) treated oral myiasis by manual removal of maggots after using chemical agents and added that use of antibiotics reduces the duration of infection and hastens the recovery period.

Jang et al. (2013) in Korea reported a case of oral myiasis in a patient 37-year-old man with a 30-year history of Becker's muscular dystrophy. He was intubated due to dyspnea 8 days prior to admission to an intensive care unit (ICU). A few hours after the ICU admission, 43 fly larvae were found during suction of the oral cavity, which were third instars of L. sericata. Dutto et al. (2013) in Italy reported a case of nosocomial myiasis 
caused by larvae of Sarcophaga (Bercaea) Africa, in an ulcer on the heel of a patient with type 2 diabetes. The ulcer was dressed when the deposition occurred. An experiment was performed in order to demonstrate the ability of Sarcophaga larvae to move through bandages and reach purulent wounds. They added that there is bad need for particular attention, education and specific protocols in hospitals in order to avoid myiasis, which can compromise the organization's reputation for hygienic standards with possible legal consequences. Zaglool et al. (2013) in Saudi Arabia reported myiasis with Sarcophaga species in the wound of a diabetic patient. Najjari et al. (2014) in Mashhad reported a 63-year old man admitted to an ICU ward for investigation. On the $35^{\text {th }}$ day of hospitalization, about $1002^{\text {nd }}$ instar larvae of Lucilia spp. were identified.

Olea et al. (2014) in Argentina reported myiasis caused by Cochliomyia hominivorax (Diptera: Calliphoridae) in a diabetic foot ulcer patient. Sukontason et al. (2014), in Thailand reported that although tropical climate of Thailand is suitably endowed with biodiversity of insects, flies of medical importance were not well investigated. Using information from literature search, fly survey approach and specialist's experience, we review database of Sarcophaga (Liosarcophaga) dux Thomson (Diptera: Sarcophagidae), one of the priorities flesh fly species of medical importance. Chaiwong et al. (2014) in Northeast Thailand reported that Chrysomya megacephala (Fabricius) (Diptera: Calliphoridae) and Musca domestica L., (Diptera: Muscidae) are synanthropic flies which are adapted to live in close association with human habitations, thereby making them likely mechanical vectors of several pathogens to humans. From 994 individual flies collected by a sweep net (555 C. megacephala and $439 \mathrm{M}$. domestica), they isolated 15 bacterial genera from the external surfaces, comprising ten genera of gram-negative bacteria and five grampositive bacteria. The commonest from both species were coagulase-negative Staphylococci, followed by Streptococcus group D nonenterococci. Human pathogenic enteric bacteria isolated were Salmonella sp., Shigella sp., Escherichia coli O157:H7, Salmonella typhi, Bacillus sp., and Enterococcus sp., of which S. typhi is the first report of isolation from these fly species. Other human pathogens included Staphylococcus aureus and Pseudomonas aeruginosa. Not only were the number of $C$. megacephala positive for bacteria significantly higher than for $M$. domestica, but they were also carrying 11-12 times greater bacterial load than $M$. domesti$c a$. They suggested that both fly species should be considered potential mechanical vectors of bacterial pathogens associated with human habitations year-round. Bunchu et al. (2014) in in Northeast Thailand isolated Toxocara eggs were isolated from $C$. megacephala collected from the fresh-food markets, garbage piles, school cafeterias, and paddy fields but not from restaurants, and concluded $C$. megacephala was a potential carrier of Toxocara eggs than M. domestica.

Use of myiasitic maggots in medicine: Throughout recorded history maggots have been used therapeutically to clean out necrotic wounds, an application known as maggot as maggot therapy. Fly larvae that feed on dead tissue can clean wounds and may reduce bacterial activity and the chance of a secondary infection. They dissolve dead tissue by secreting digestive enzymes onto the wound as well as actively eating the dead tissue with "mouth hooks," two hard, probing appendages protruding on either side of the mouth (David and William, 2006). Maggot therapy-also known as maggot debridement therapy (MDT), larval therapy, larva therapy, or larvae therapy- is the intentional introduction by a health care practitioner of live, disinfected green bottle fly larvae into non-healing skin and soft tissue wound(s) of a human or other animal for the purpose of selectively cleaning out only the necrotic (dead) tissue within a wound in order to 
promote wound healing. Maggot therapy has a long history and prehistory. The indigenous people of Australia used maggot therapy, and so do the Hill Peoples of Northern Burma, and possibly the Mayans of Central America. Surgeons in Napoleon's armies recognized that wounded soldiers with myiasis were more likely to survive than those without the infestation. In the American Civil War, army surgeons treated wounds by allowing blowfly maggots to clean away the decayed tissue. Dr. William Baer, an orthopedic surgeon at Johns Hopkins during the late 1920 s, used maggot therapy to treat a series of patients with osteomyelitis, an infection of bone or bone marrow. The idea was based on an experience in the WorldWar I in which two soldiers presented to him with broken femurs after having lain on the ground for seven days without food and water (William, 1931). Mumcuoglu (2001) reported that sterile maggot debridement therapy (MDT) was first introduced in the US in 1931 and was used until mid-1940s in over 300 hospitals. With the antibacterial advent, MDT became rare until the early 1990s, but re-introduced first in the US, and later in Israel, the UK, Germany, Sweden, Switzerland, Ukraine and Thailand. Maggots were approved by the FDA as a "medical device" only in 2004 (along with leeches in the same year). Maggots were the first live organism to be marketed in the US according to FDA regulations, and are approved for treating neuropathic (diabetic) foot ulcers, pressure ulcers, venous stasis ulcers, and traumatic and post-surgical wounds that are unresponsive to conventional therapies (Rita, 2004). Besides, Demirel et al. (2014) in Turkey stated that diabetes, coronary artery disease and low socio-economic level as well as the presence of an open, neglected wound were attributed as the most important predisposing factors that led to the development of myiasis in this patient. It should be kept in mind that the diabetic patients with open wounds may develop myiasis especially in the summer months and larvae can cause progressive wound infection. However, only a small number of flies that cause human myiasis are used in medicine (Francesconi and Lupi, 2012).

In Egypt, Steyskal and El-Bialy (1967) listed the Egyptian Diptera, among which 184 were myiasis producing dipterous flies. They were in alphabetical orders; Calliphoridae (12 species), Gasterophilidae (5 species), Muscidae (63 species), Oestridae (5 species), Piophilidae (2 species) and Sarcophagidae (97 species) and gave key for families identifications. Shaumar et al. (1989) established a key of all known Egyptian species of Calliphoridae to genera and species accompanied by synonyms in the light of modern taxonomic concepts. Eight genera are recorded including 14 species and added Hemipyrellia pulchra (Wied) as a record. So, many authors dealt with animal and zoonotic myiasis. Regarding human myisis, Hilmy (1954) reported a case of urinary myiasis caused by the cheese skipper larvae. Ghawaby and Morsy (1976) in Ain-Shams University's Hospitals reported human traumatic myiasis caused by Wohlfahrtia magnifica. Boulaqi et al. (1983) in Cairo reported aural myiasis in a hospitalized patient. Antonios and Galal (1988) reported human intestinal myiasis. El Kadery and el-Begermy (1989) reported aural myiasis caused by W. magnifica. Morsy and Farrag (1991) demonstrated ophthalmomyiasis due to Oestrus ovis and W. magnifica Fawzy (1991) described three human cases of otitis media associated with aural myiasis, caused by larvae of W. magnifica (two cases and S. falculata (one case). El-Serougi (1991) reported human urinary myiasis. Saleh and el Sibae (1993) reported three cases of nosocomial urino-genital myiasis due to Piophila casei. Fekry et al. (1993) found Oestrus ovis infesting the eyes and the nose of a camel keeper family. Tantawi and Greenberg (1993) stated that the length of the oldest maggots recovered from a body often gave an accurate estimate of the time since death. The maggots' length of Protophormia ter- 
raenovae of known age, at peak of feeding was measured after 5 days immersion in one of 15 killing and preservative solutions, some of which are routinely used at autopsy and in forensic entomology; controls were killed in boiling water. They added that larvae of Calliphora vicina underwent even greater shrinkage. They concluded that which the crop length, which may be useful in age estimates of post-feeding larvae, was not altered significantly for forensic purposes in these solutions. The highly significant alterations in maggot length underscore a need for standardization in the treatment of maggots collected at the crime scene and at autopsy if their length is to be interpreted in a valid and consistent way. Fekry et al. (1997) reported a family of five persons infested in the eyes (5) and nose (2) with the larvae of $O$. ovis. They concluded that the physicians in the MOH rural health units should keep in mind opthalmomyiasis when dealing with non-specific catarrhal conjunctivitis particularly those people who were concerned with rearing of farm animals.

Mazyad and Rifaat (2005) found intestinal myiasis caused by Megaselia scalaris larvae. Tantawi et al. (2010) reported an accidental involvement of $L$. cuprina in MDT in Alexandria, Egypt, which proved to be safe and effective. Laboratory colonies of $L$. sericata (species regularly used in MDT) at the Alexandria Faculty of Science were renewed by Lucilia flies collected as third instar larvae on exposed rabbit carcasses. Flies from the new colonies were successfully used to heal the diabetic foot wounds of two patients at Alexandria Main University Hospital. Analysis of DNA sequences and adult and larval morphology then revealed that these flies were and still are L. cuprina. Breeding of this species in carrion in Alexandria is a new record. Despite the safety of this strain of L. cuprina in MDT, entomologists rearing blow flies for the purpose of wound debridement should regularly maintain high quality assurance of their species' identity to avoid possible clinical complica- tions that may result from the introduction of an unexpected and invasive species to their laboratory colonies.

Ahmad et al. (2011) in Al-Minia City reported four cases of gastric or intestinal myiasis are reported. The patients were males; a 10 years old child, and 40 years old man) and females; a 18 years old girl, and a 50 years old woman. Three complained of offensive hematemesis of bright red blood, including minute moving worms in the vomitus. The fourth case complained of abdominal distention, nausea, vomiting, and diarrhea. The stool of case 2 was mixed with blood, and minute moving worms were observed in the stool. The recovered larvae were $2^{\text {nd }}$ or $3^{\text {rd }}$ stages of Sarcophaga species, and the larvae isolated from case 2 were the third stage larvae of Sarcophaga species, as well as $3^{\text {rd }}$ stage larvae of Oestrus species.

Abosdera and Morsy (2013) studied the clinical pictures and pathogenesis of human oral cavity myiasis. Thirteen cases were demonstrated for the first time in Egypt, ten children and the parents of three children. The extracted larvae were Lucilia sericata (four cases), Wohlfahrtia magnifica (three cases), Oestrus ovis (three children and their parents) and Musca domestica vicina (one case). The presence of $O$. ovis in three children and their parents recommended zoonotic nosocomial myiasis. The predisposing factors were mouth breathing, incompetent lips, low socioeconomic condition, malnutrition, and inability of a child to perform daily activities due to the neurodegenerative disease. Hassan et al. (2014) used L. cuprina maggots for the treatment of an artificial wound made in the diabetic foot of rabbit. The maggots were sterilized and put directly on the wound after being dressed without any antibiotics. Several cycles of maggots were put on the wound. They found that the treatment of the diabetic foot was observed after 13 days. After this period the wound was completely healed and become free of microbial contamination. The new tissues were observed to close the wound. 
Regarding animals, Hilali et al. (1987) examined stomachs 118 donkeys at postmortem from March 1982 to February 1983. They found $G$. intestinalis larvae clustered in groups near the boundary of the glandular and non-glandular epithelium in $98.3 \%$ of them with highest numbers in July and lowest numbers in October. Larvae were mainly attached near the pylorus and first part of the duodenum and infested $87.3 \%$ of donkeys with highest incidence in December and lowest in October. The ratio of the second and third instars of $G$. intestinalis to G. nasalis ranged from $71 \%$ to $29 \%$. Morsy et al. (1991) collected a total of nine myiasis producing dipterous flies from Cairo and Giza abattoirs. These were Musca d. vicina, Calliphora vicina, Chrysomyia albiceps, $C$. marginalis, Lucilia sericata, L. cuprina, Sarcophaga haemorrhoidalis, Wohlfahrtia magnifica and Oestrus ovis. Zayed (1992) found that Rhinoestrus purpureus pupal duration infesting donkeys was affected by temperature but not by $\mathrm{RH}$, and that the optimum temperature and $\mathrm{RH}$ for obtaining normal active flies were 32 degrees $\mathrm{C}$ and $30 \%$, respectively. Omar (1995) stated that Chrysomyia albiceps was first species to arrive at carrion to lay its eggs on it almost immediately under favorable conditions. Field studies showed that although other flies arrive at the carrion shortly following Chrysomyia, as decomposition progresses, its larvae are the major component predominates, and the common fly emerging from carrion is its adults. First instar larvae is entirely microphagous, but the $2^{\text {nd }}$ and early $3^{\text {rd }}$ instar larvae may be facultative predaceous on other dipteran larvae (Muscina and Parasarcophaga) as an alternative food source under crowded or starved conditions. Cannibalism, $2^{\text {nd }}$ and early $3^{\text {rd }}$ instars preying on the $1^{\text {st }}$ instar larvae and on them has also been found. $C$. albiceps may be considered as beneficial biological control agent to help in reducing populations of carrion flies of medical and veterinary importance owing to their significant role in causing the different kind of myiasis of man and animals. The second instar is less inclined than the early $3^{\text {rd }}$ instar to serve as a predator. The numerous heavily sclerotized spines and fleshy processes of the robust and powerful preyer early $3^{\text {rd }}$ instar larvae help in subduing the prey while their strong mouth-hooks are used to penetrate the bodies of the other larvae for fluid extraction. Amin et al. (1997a) in North Sinai studied myiasis of sheep and goats and identified of 21 species of myiasis producing flies. The predominant species was Musca domestica followed by L. sericata and the least abundant was M. albina. In general, sheep were more infested with wound myiasis than goats. The overall infestation rate was high in summer, followed by spring then autumn. The least rate of infestation was winter. As to the different areas examined, the high rate of infestation was in Bir Al-Abd, followed by Al Hasanah, Al Arish, Al Sheikh-Zowaid and lastly Rafah. The factors predisposing to wound myiasis in a descending order of importance in goats were open wound, shearing wound, caseous lymphadenitis, foot rot, faecal staining, ophthalmo- or facial eczema, horn fracture, rumen fistula and lastly posterior paralysis. In sheep, the most important cause was caseous lymphadenitis followed by foot rot, then open wound and faecal staining, shearing wound, and ophthalmo or facial eczema otherwise more or less the same as in goats. It is concluded that myiasis among edible animals is a problem of veterinary and economic importance. The clinical features range between mild annoyance to severely disfiguring or fatal. Amin et al. (1997b) in Cairo abattoir examined1200 slaughtered sheep heads and found 104 (8.67\%) were infested with $O$. ovis maggots. Sheep were parasitized all the year round with more or less maximum number $(12.5 \%)$ in September. The sex ratio of parasitized sheep (female to male) was 1:2.71. A total of 556 maggots were recovered over a year with a peak in March (12.6\%). The peak for the first instar larvae recovered was September (17.4\%), 
for the second instar was March (15.7\%) and for the third instar was June (11.6\%). Older sheep were more infested $(12.0 \%)$ with oestrosis than smaller ones $(6.87 \%)$.

Amin et al. (1998) in Al Marg District reported sixteen species of dipterous flies. The predominant species was Musca domestica followed by $L$. sericata and the least abundance was $W$. magnifica. The overall abundance was in summer followed by Spring and the least was in Winter. The most attractive bait was liver for members of family Calliphoridae and meat for members of family Muscidae and Family Sarcophagidae.

Morsy et al. (1998a) North Sinai a total of 43 living goats out of $2040(2.11 \%)$ was naturally infested with Przhevalskiana silenus (Brauer) mainly in winter. Besides, nodule caused of $P$. silenus larvae were recovered from 32 out of 98 (32.65\%) slaughtered goats in $\mathrm{Al}$ Arish abattoir mainly in summer. The overall infestation rate among slaughtered goats was $11.68 \%$. Adult flies were collected by baited traps from Bir Al Abd and $\mathrm{Al}$ Hasanah in late spring and early summer. Morsy et al. (1998b) in Al Arish studied the monthly and seasonal prevalence of $C$. titillator larvae in slaughtered camels. The rate of camel infestation was $25 \%$. The highest prevalence month was October and the highest prevalence season was autumn. The three larval instars were demonstrated in the infested camels. However, the 3rd instars were the predominant stage $(60.59 \%)$, followed by the $2^{\text {nd }}$ instars $(30.58 \%)$ and then the $1^{\text {st }}$ instars $(8.83 \%)$. They concluded that the control of the adult $C$. titillator and its larval instars is a must for the sake of the animal and for the human welfare. Morsy et al. (1999) evaluated ELISA kit hypodermosis in detecting antibodies against 2 oestrid larvae, Przhevalskiana silenus in goats and $C$. titillator in camels. Antibodies against $P$. silenus were detected in 38 out of $40(95 \%)$ infested goats and negative results among the control group. With $C$. titillator, antibodies were detected in 39 out of $40(97.5 \%)$ infested camels. But, one of the control
(10\%) gave false seropositivity. ELISA hypodermosis diagnosed antibodies against $P$. silenus and $C$. titillator. So, there were cross reactions between anti-Hypoderma antibodies and antibodies against both Przhevalskiana and Cephalopina. ELISA proved to be an easy and economic tool to diagnose myiasis infestation when direct examination was not a simple mean and/or for epidemiological studies

Besides, Hilali and Fahmy (1993) reported trypanosome-like epimastigotes in C. titillator larvae infesting Egyptian camels infected with Trypanosoma evansi and Haridy et al. (2011) reported Egyptian zoonotic T. evansi. Morsy et al. (1999) developed and evaluated an ELISA-Kit hypodermosis for the diagnosis of the $P$. silenus in goats and $C$. titillator in camels. Tantawi et al. (2010) in Alexandria used $L$. cuprina in maggot debridement as successful therapy.

As to control, Guimaraes et al. (1963) in Rio de Janeiro used thiabendazole ${ }^{\circledR}$ in treating a hospitalized patient with oral myiasis. Amin (1998) in Saudi Arabia used ivermectin was used in-vitro against $L$. sericata larvae. The $\mathrm{LC}_{50}$ was found to be 9 ppm (0.76$1.5)$ and the slope function was 0.59 . He added that that ivermectin is a safe and very effective larvicide for $L$. sericata.

In Egypt, Nagaty et al. (1960) in-vitro evaluated the larvicidal efficacy of seven organic and inorganic compounds against Musca d. vicina and Ch. albiceps reared on minced meat. Morsy et al. (1998c) used the volatile oils of Chenopodium ambrosioides (American wormseed) and Thymus vulgaris (Tyme) against the $3^{\text {rd }}$ stage larvae of $L$. sericata. The $\mathrm{LC}_{50}$ confidence limits were $70 \mathrm{ppm}$ and $130 \mathrm{ppm}$ for both volatile oils respectively. They concluded that the use of these plant volatile oils, which are widely, distributed in the Egyptian flora, cheaper, more safe and without any pollution or hazard, proved to be effective. Morsy et al. (1998d) evaluated the solvent extracts of three Egyptian medicinal plants in controlling the third stage larvae of $C$. albiceps. 
Mazyad et al. (1999) evaluated the volatile oils of three plants against adult Lucilia sericata. The $\mathrm{LC}_{50}$ was 80 ppm by Anethum graveolens, 180 ppm by Conyza dioscoridis and $130 \mathrm{ppm}$ by Mentha microphylla. The slope functions were $1.9,1.79$ and 2.2 respectively. Morsy and Mazyad (2000) feed newly moulted $3^{\text {rd }}$ stage larvae of L. sericata on mixed $B$. thuringiensis var. israelensis (B.t. H-14) with minced liver in different concentrations. The $\mathrm{LC}_{50}$ was 9 ppm (0.76$1.5)$ and the slope function was 0.59 . They concluded that bacterium which is safe and friendly proved to be effective against the myiasis producing $L$. sericata larvae

Mazyad and Raheem (2001) reported that Bacillus t. israelensis (B.t. serotype $\mathrm{H}-14$ ) and its toxins have a marked lethal effect on both the eggs and the newly moulted 3rd stage larvae of $C$. titillator. The Bacillus was less effective than Bacillus and its toxins on both the eggs and larvae. On the other hand, the larvae were more affected by both Bacillus and Bacillus and its toxins than the eggs. Prolonged exposure time showed more lethal effect. Mazyad and Soliman (2001) evaluated the essential oil of E. globulus leaves or camphor against the maturation of Oestrus ovis larvae. Camphor at concentrations 1:0 \& 1.1 showed $100 \%$ mortality rate. At concentrations of 1:2-1:6 mortality rate was between $45-98 \%$. Besides, 38 or $27.5 \%$ of the developed pupae emerged to adults but only $36.8 \%$ were fertile. They recommended camphor oil in controlling zoonotic myiasis producer, $O$. ovis. Khater and Khater (2009) evaluated the insecticidal effect of fenugreek (Trigonella foenum-graecum), celery (Apium graveolens), radish (Raphanus sativus), and mustard (Brassica compestris) against the $3^{\text {rd }}$ larval instars of $L$. sericata by ingestion assays. They found that $\mathrm{LC}_{50}$ values were $2.81,4.60,6.93$, and $7.92 \%$ for fenugreek, celery, radish, and mustard, respectively. The pupation rate was strongly decreased after treatment with $16 \%$ fenugreek and celery, and adult emergence was suppressed after treatment of larvae with $8 \%$ mustard, $12 \%$ radish, and $16 \%$ fenugreek and celery oils, with emerged males exceeded the number of females. They concluded that these oils may represent new and safe potential insecticides for the control of blowflies. Khater et al. (2011) studied the insecticidal effectiveness of four commercially available essential oils of lettuce ( $\mathrm{Lac}$ tuca sativa), chamomile (Matricaria chamomilla), anise (Pimpinella anisum), rosemary (Rosmarinus officinalis) against $3^{\text {rd }}$ larval instars of $L$. sericata regarding their sublethal concentrations on pupation rates, adult emergences, sex ratios, and morphological anomalies were also determined. They concluded that the four tested oils are inexpensive and may represent new botanical insecticides for controlling blowflies. Khater (2014) evaluated the efficacy of essential oils (EOs) of pumpkin, Cucurbita maxima; lupinus, L. luteus; garlic oil, Allium sativum; and peppermint, Mentha piperita, against the $3^{\text {rd }}$ larval stage of $C$. titillator by immersion tests. The positive control group was treated with ivermectin and the negative control one was treated with distilled water and few drops of Tween 80. Larvae were reared until adult emergence. The data indicated that complete larval mortalities were reached $24 \mathrm{~h}$ post treatment (PT) with $2 \%$ pumpkin, $7.5 \%$ garlic and peppermint, $30 \%$ lupinus, and $0.15 \%$ ivermectin. The lethal values, $\mathrm{LC}_{50 \mathrm{~s}}$, were $0.20,0.44,0.42,0.47, \&$ $0.03 \%$, respectively. Pumpkin and ivermectin were 2 and 17 times, respectively, more effective than the other EOs. Ivermectin was seven times more intoxicating than pumpkin oil. Formation of pupae had been stopped after treatment of larvae with $2 \%$ pumpkin, $7.5 \%$ garlic and peppermint, $30 \%$ lupines, and $0.04 \%$ ivermectin. The adult emergence was completely ceased following treatment of larvae with $0.5 \%$ EOs and $0.04 \%$ ivermectin. The morphological abnormalities were pronounced after treatments, and peppermint oil was the foremost cause of deformation in larvae (44\% PT with $7.5 \%$ ) and pupae (40\% PT with 2\%). Pumpkin oil (6 
$\%)$ proved to be the drug of choice to control C. titillator. EOs proved much safer than ivermectin regarding health and environmental issues.

Unfortunately, El-Azazy (1992) in Libya reported that 468 cases of screwworm myiasis were recorded in seven species of livestock and 229 humans, mainly children. Cattle and sheep were the commonest hosts. In cattle, the specific infested site was the umbilicus of neonates; in sheep in fatty tail. Myiasis reached its peak in autumn, but disappeared abruptly in winter. Screwworm distribution was confined to the northwest of Libya, with a possibility of infestation of other countries, particularly Egypt.

\section{Conclusion}

No doubt, myiasis is a problem of medical and veterinary importance worldwide. It affects human welfare both directly and indirectly. This study updates the knowledge and might help in adapting and implementing appropriate, timely, and confirmatory diagnostic procedures. When myiasis occurs in a patient after hospitalization the disease is termed nosocomial myiasis, an infrequent phenomenon, but risks. Besides, one must consider the potential neglected role of these flies in carrying pathogenic organisms as viruses, fungi, bacteria, and parasites as mechanical vectors to humans.

\section{References}

Abosdera, M.M, Morsy, TA, 2013: Oral cavity myiasis in children: First demonstration in Egypt with general review. J. Egypt. Soc. Parasitol. 43, 3:737-46.

Ahmad, AK, Abdel-Hafeez, EH, Makhloof, M, Abdel-Raheem, EM, 2011: Gastrointestinal myiasis by larvae of Sarcophaga sp. and Oestrus sp. in Egypt: report of cases, and endoscopical and morphological studies. Korean J. Parasitol. 49, 1:51-7.

Al-Wahbi, AM, 2006: The diabetic foot in the Arab world. Saudi Med J. 27:147-53.

Amin, AM, 1998: In vitro effect of ivermectin on the larvae of Lucilia sericata Meigen in Saudi Arabia. J. Egypt. Soc. Parasitol. 28, 1:53-8.

Amin, AR, Morsy, TA, Shoukry, A, Mazyad,
SA, 1997a: Oestrid head maggots in slaughtered sheep in Cairo abattoir. J. Egypt. Soc. Parasitol. 27, 3:855-61.

Amin, AR, Shoukry, A, Morsy, TA, Mazyad, SA, 1997b: Studies of wound myiasis among sheep and goats in North Sinai Governorate, Egypt. J. Egypt. Soc. Parasitol. 27, 3:719-37.

Amin, AR, Morsy, TA, Shoukry, A, Mazyad, SA, 1998: Studies on myiasis producing flies collected by bait traps at Al Marg (Qalyobia Governorate), Egypt. J. Egypt. Soc. Parasitol. 28, 1:45-51

Amitay, M, Efrat, M, McGarry, JW, Shinwell, ES, 1998: Nosocomial myiasis in an extremely premature infant caused by the sheep blowfly Lucilia sericata. Pediatr. Infect. Dis. J. 17, 11: 1056-7

Antonios, SN, Galal, AA, 1988: Intestinal myiasis in an Egyptian patient. J. Egypt. Soc. Parasitol. 18, 2:723-4.

Assaad-Khalil, SH, Al Arouj, M, Almaatouq, M, Amod, A, Assaad, SN, et al, 2013: Barriers to the delivery of diabetes care in the Middle East and South Africa: a survey of 1,082 practising physicians in five countries. Int. J. Clin. Pract. 67, 11: 1144-50.

Bilal, DI, Uğur, US, Nermin, IŞ, 2012: Myiasis in animals and human beings in Turkey. J. Fac. Vet. Med. 18: 37-42.

Bunchu, N, Silaram, M, Sukontason, K, Sukontason, KL, Chaiwong, T, 2014: Isolation of Toxocara eggs from flies in Northeast Thailand. J. Med. Assoc. Thai. 97, 4:S25-8.

Chaiwong, T, Srivoramas, T, Sueabsamran, P, Sukontason, K, Sanford, MR, et al, 2014: The blow fly, Chrysomya megacephala, and the house fly, Musca domestica, as mechanical vectors of pathogenic bacteria in Northeast Thailand. Trop. Biomed. 31, 2:336-46.

Chan, JC, Lee, JS, Dai, DL, Woo, J, 2005: Unusual cases of human myiasis due to Old World screwworm fly acquired indoors in Hong Kong. Trans. Roy. Soc. Trop. Med. Hyg. 99, 12: 914-8.

Couppié, P, Roussel, M, Rabarison, P, Sockeel, MJ, Sainte-Marie, D, et al, 2005: Nosocomial nasal myiasis owing to Cochliomyia hominivorax: a case in French Guiana. Int. J.

Dermatol. 44, 4:302-3.

Daniel, M, Srámová, H, Zálabská, E, 1994: Lucilia sericata (Diptera: Calliphoridae) causing hospital-acquired myiasis of a traumatic wound. J. Hosp. Infect. 28, 2:149-52. 
David, J, and William, P, 2006: In: Markell and Voge's Medical Parasitology: 9th Edition. Missouri: Saunders Elsevier.

De Kaminsky, RG, 1993: Nosocomial myiasis by Cochliomyia hominivorax in Honduras. Trans. R. Soc. Trop. Med. Hyg. 87, 2:199-200.

Demirel, KF, Orkun, O, Cakmak, A, Inkaya, AC, Erguven, S, 2014: Cutanous myiasis caused by Sarcophaga spp. larvae in a diabetic patient. Mikrobiyol. Bul. 48, 2:356-61.

Dutto, M, Bertero, M, 2011: Cutaneous superficial myiasis: report of a rare nosocomial parasitic disease caused by Sarcophaga spp. (diptera, sarcophagidae). Cent. Eur. J. Publ. Hlth. 19, 4: 232-4.

Dutto, M, Pellegrino, M, Vanin, S, 2013: Nosoocomial myiasis in a patient with diabetes. J. Hosp. Infect. 83, 1:74-6.

el Kadery, AA, el-Begermy, MA, 1989: Aural myiasis caused by Wohlfahrtia magnifica. J. Egypt. Soc. Parasitol. 19, 2:751-3.

El-Azazy, OM, 1992: Observations on the New World screwworm fly in Libya and the risk of its entrance into Egypt. Vet. Parasitol. 42, 3/4:30310.

El-Boulaqi, HA, Amin, FM, Bassiouny, GA, El-Rifaie, SA, 1983: Aural myiasis in Cairo. J. Egypt. Soc. Parasitol.13, 2:547-50.

El-Hilaly, R, Elshazly, O, Amer, A, 2013: The role of a total contact insole in diminishing foot pressures following partial first ray amputation in diabetic patients Foot (Edinb). 23, 1:6-10

El-Serougi, AO, 1991: A case of urinary myiasis due to Piophila casei. J. Egypt. Soc. Parasitol. 21, 2:595-6

El-Sharawy, MA, Naim, M, Greish, S, 2012: Human CD34+ stem cells promote healing of diabetic foot ulcers in rats. Interact. Cardiovasc. Thorac. Surg. 14, 3:288-93.

Fawzy, AF, 1991: Otitis media and aural myiasis. J. Egypt. Soc. Parasitol. 21, 3:883-5.

Fekry, AA, el Serougi, AO, Ayoub, S A, 1997: Oestrus ovis (sheep nasal fly) infesting the eyes and the nose of a camel keeper family. J. Egypt. Soc. Parasitol. 27, 2: 493-6.

Francesconi, F, Lupi, O, 2012: Myiasis. Clin. Microbiol. Rev. 25, 1:79-105

Ghawaby, MH, Morsy, TA, 1976: Traumatic myiasis in man due to Wohlfahrtia magnifica. J. Egypt. Soc. Parasitol. 6:19-22.

Greco, JB, Sacramento, E, Tavares-Neto, J, 2001: Chronic ulcers and myasis as ports of en- try for Clostridium tetani. Braz. J. Infect. Dis. 5, 6:319-23.

Greenberg, B, 1973: In: Flies and Disease, Volume II, $1^{\text {st }}$ edition. Princeton University Press.

Guimaraes, SA, Marzola, C, Okamoto, T, 1963: Oral therapy of myiasis Linearis migrans (creeping disease) by using thiabendazole. Hospital. (Rio de J.). 63:1173-80

Hassan, MI, Hammad, KM, Fouda, MA, Kamel, MR, 2014: The using of Lucilia cuprina maggots in the treatment of diabetic foot wounds. J. Egypt. Soc. Parasitol.44, 1:125- 9

Hemmings, SC, Matthews, KJ, Alexander, J, 2007: Human myiasis in western Jamaica: five years after the implementation of a screwworm eradication program. West Indian Med. J. 56, 4: 341-5.

Hilali, M, Derhalli, FS, Baraka, A, 1987: Incidence and monthly prevalence of Gasterophilus spp. larvae (Diptera: Gasterophilidae) in the stomach of donkeys (Equus asinus) in Egypt. Vet. Parasitol. 23, 3/4:297-305.

Hilali, M, Fahmy, MM, 1993: Trypanozoonlike epimastigotes in the larvae of Cephalopina titillator (Diptera: Oestridae) infesting camels (Camelus dromedarius) infected with Trypanosoma evansi. Vet. Parasitol. 45, 3/4:327-9.

Hilmy, IS, 1954: The cheese skipper as cause of a case of urinary myiasis in Egypt. J. Egypt. Med. Assoc. 37, 8:969-82.

Hope, FW, 1840: On insects and their larvae occasionally found in the human body. Trans. R. Entomol. Soc. London, 2: 256-71.

Jacobson, JA, Kolts, RL, Conti, M, Burke, J P, 1980: Hospital-acquired myiasis. Infect. Control 1, 5:319-20.

Jang, M, Ryu, SM, Kwon, SC, Ha, JO, Kim, YH, et al, 2013: A case of oral myiasis caused by Lucilia sericata (Diptera: Calliphoridae) in Korea. Korean J. Parasitol. 51, 1:119-23.

Joo, CY, Kim, JB, 2001: Nosocomial submandibular infections with dipterous fly larvae. Korean J. Parasitol. 39, 3:255-60.

Josephson, RL, Krajden, S, 1993: An unusual nosocomial infection: nasotracheal myiasis. J. Otolaryngol. 22, 1:46-7.

Kathleen, G, 2005: Age-old therapy gets new approval: Advances in Skin \& Wound Care. January/ February 2005.

Khater, HF, 2014: Bioactivities of some essential oils against the camel nasal botfly, Cephalopina titillator. Parasitol. Res. 113, 2:593-605. 
Khater, HF, Hanafy, A, Abdel-Mageed, AD, Ramadan, MY, El-Madawy, RS, 2011: Control of the myiasis-producing fly, Lucilia sericata with Egyptian essential oils. Int. J. Dermatol. 50, 2:187-94.

Khater, HF, Khater, DF, 2009: The insecticidal activity of four medicinal plants against the blowfly Lucilia sericata (Diptera: Calliphoridae). Int. J. Dermatol. 48, 5:492-7.

Kim, JS, Seo, PW, Kim, JW, Go, JH, Jang, SC, et al, 2009: A nasal myiasis in a 76-year-old female in Korea. Kore. J. Parasitol. 47, 4:405-7.

Lee, YT, Chen, TL, Lin, YC, Fung, CP, Cho, WL, 2011: Nosocomial nasal myiasis in an intubated patient. Chin. Med. Assoc. 74, 8:369-71.

Maleki Ravasan, N, Shayeghi, M, Najibi. B, Oshaghi, MA, 2012: Infantile nosocomial myiasis in iran. J. Arthropod Borne Dis. 6, 2:156-63.

Mazyad, SA, El-Serougi, AO, Morsy, TA, 1999: The efficacy of the volatile oils of three plants for controlling Lucilia sericata. J. Egypt. Soc. Parasitol. 29, 1:91-100.

Mazyad, SA, Raheem, MA, 2001: Study on the effect of Bacillus thuringiensis (B.t. serotype H14) and its toxins against Cephalopina titillator (Clark), the Egyptian camel myiasis producing dipterous fly. J. Egypt. Soc. Parasitol. 31, 3:81522.

Mazyad, SA, Soliman, M, 2001: Laboratory evaluation of the insecticidal activity of camphor on the development of Oestrus ovis larvae. J. Egypt. Soc. Parasitol. 31, 3:887-92

Mielke, U, 1997: Nosocomial myiasis. J. Hosp. Infect. 37, 1:1-5.

Mielke, U, Schlote, A, 1980: Hospital infection resulting from maggots. Z. Arztl. Fortbild (Jena). 74, 11:556-8.

Minár, J, Herold, J, Elisková, J, 1995: Nosocomial myiasis in Central Europe. Epidemiol. Mikrobiol. Immunol. 44, 2:81-3.

Morsy, TA, 2012a: The causes of skin lesions in the returning travelers: With special reference to Egypt. J. Egypt. Soc. Parasitol. 42, 1:135-56.

Morsy, TA, 2012b: Insect bites and what is eating you? J. Egypt. Soc. Parasitol. 42, 2:291-308. Morsy, TA, Farrag, AM, 1991: Two cases of human ophthalmomyiasis. J. Egypt. Soc. Parasitol. 21, 3:853-5.

Morsy, TA, Mazyad, SA, 2000: Bacillus thuringiensis var. israelensis (B.t. serotype $\mathrm{H}-14$ ) against Lucilia sericata third stage larvae. J. Egypt. Soc. Parasitol. 30, 2:573-80.
Morsy, TA, Fayad, ME, Salama, MMI, Sabry, AA, El Serougi, AOM, 1991: Some myiasis producers in Cairo and Giza abattoirs. J. Egypt. Soc. Parasitol. 21, 2:539-46.

Morsy, TA, Shoukry, A, Mazyad, SA, Abou Gamra, MM, 1998a: The goat warble fly, Przhevalskiana silenus (Brauer) in north Sinai, Egypt. J. Egypt. Soc. Parasitol. 28, 2:373-8.

Morsy, TA, Aziz, AS, Mazyad, SA, Al Sharif, KO, 1998b: Myiasis caused by Cephalopina titillator (Clark) in slaughtered camels in $\mathrm{Al}$ Arish Abattoir, North Sinai Governorate, Egypt. J. Egypt. Soc. Parasitol. 28, 1:67-73.

Morsy, TA, Shoukry, A, Mazyad, SA, Makled, KM, 1998c: The effect of the volatile oils of Chenopodium ambrosioides and Thymus vulgaris against the larvae of Lucilia sericata (Meigen). J. Egypt. Soc. Parasitol. 28, 2:503-10.

Morsy, TA, Mazyad, SAM, El Shar-kawy, IMA, 1998d: The larvicidal activity of solvent extracts of three medicinal plants against the third instar larvae of Chrysomyia albiceps. J. Egypt. Soc. Parasitol. 28, 3:699-709.

Morsy, TA, Farrag, AM, Mazyad, S A, AbouGamra, MM, 1999: Evaluation of ELISA kit hypodermosis in serodiagnosis of Przhevalskiana silenus in goats and Cephalopenia titillator in camels. J. Egypt. Soc Parasitol. 29, 3: 709-19.

Mowlavi, G, Nateghpour, M, Teimoori, S, Amin, A, Noohi, F, et al, 2011: Fatal nosocomial myiasis caused by Lucilia sericata. J. Hosp. Infect. 78, 4:338-9.

Mumcuoglu, KY, 2001: Clinical applications for maggots in wound care. Am. J. Clin. Dermatol. 2, 4:219-27.

Nagaty, HF, Rifaat, MA, Morsy, TA, 1960: Investigation of larvicidal action of some organic and inorganic compounds against two myiasis producing dipterous larvae (Musca domestica var. vicina and Chrysomyia albiceps). J. Egypt. Pub. Hlth. Assoc. 35, 3:145-52.

Najjari, M, Shafiei, R, Fakoorziba, MR, 2014: Nosocomial myiasis with Lucilia sericata (Diptera: Calliphoridae) in an ICU patient in Mashhad, Northeastern of Iran. Arch. Iran Med. 17, 7:523-5.

Nazni, WA, Jeffery, J, Lee, HL, Lailatul, AM, Chew, WK, et al, 2011: Nosocomial nasal myiasis in an intensive care unit. Malays. J. Pathol. 33, 1:53-6.

Olea, MS, Centeno, N, Aybar, CA, Ortega, ES, Galante, GB, et al, 2014: First report of myiasis caused by Cochliomyia hominivorax (Diptera: 
Calliphoridae) in a diabetic foot ulcer patient in Argentina. Korean J. Parasitol. 52, 1:89-92.

Omar, AH, 1995: Cannibalism and predation behavior of the blowfly, Chrysomyia albiceps (Wiedemann) larvae (Diptera: Calliphoridae). J. Egypt. Soc. Parasitol. 25, 3:729-43

Otranto, D, Colwell, DD, Milillo, P, Di Marco, V, Paradies, P, et al, 2004:Report in Europe of nasal myiasis by Rhinoestrus spp. in horses and donkeys: seasonal patterns and taxonomical considerations. Vet. Parasitol. 122, 1:79-88.

Patton, WS, 1922: Notes on the myiasis producing Diptera of man and animals. Bull. Entomol. Res. 12:239-61.

Pérez-Giraldo, C, Márquez, I, Blanco, MT, Muñoz, Del Rey JR, et al, 2012: A case of human oral myiasis by Lucilia sericata in a hospitalized patient in Extremadura, Spain. Case Rep. Med. 792683. doi: 10.1155/792683.

Quesada-Lobo, L, Troyo, A, Calderón-Arguedas, Ó, 2012: First report of nosocomial myiasis by Lucilia cuprina (Diptera: Calliphoridae) in Costa Rica. Biomedica 32, 4:485-9.

Raffaldi, I, Scolfaro, C, Pinon, M, Longo, S, Savoia, D, et al, 2013: A strange gingival swelling in an Italian child: A case of oral myiasis. Infez. Med. 21, 1:56-9.

Rita. R, 2004: Maggots and leeches: Good medicine. Usatoday.Com. Retrieved 2013-11-0

Rubio, C, Ladrón de Guevara, C, Martín, M A, Campos, L, Quesada, A, et al, 2006: Cutaneous myiasis over tumor-lesions: presentation of three cases. Act. Dermosifiliogr. 97, 1:39-42. Saleh, MS, el Sibae, MM, 1993: Urino-genital myiasis due to Piophila casei. J. Egypt. Soc. Parasitol. 23, 3:737-9.

Sesterhenn, AM, Pfützner, W, Braulke, DM, Wiegand, S, Werner, JA, et al, 2009: Cutaneous manifestation of myiasis in malignant wounds of the head and neck. Eur. J. Dermatol. 19, 1:64-8.

Sharma, A, 2012: Oral myiasis is a potential risk in patients with special health care needs. J. Glob. Infect. Dis. 4, 1:60-1.

Sharma, A, Hedge, A, 2010: Primary oral myiasis due to Chrysomya bezziana treated with Ivermectin: A case report. J. Clin. Pediatr. Dent. 34, 3:259-61.

Shaumar, NF, Mohammed, SK, Mohammed, SA, 1989: Keys for identification of species of family Calliphoridae (Diptera) in Egypt. J. Egypt. Soc. Parasitol. 19, 2:669-81.
Show, KR, 1974: Insects and Diseases. New York, Halsted Press.

Smith DR, Clevenger RR, 1986: Nosocomial nasal myiasis. Arch. Pathol. Lab, Med. 110, 5: 439-40.

Soliman, MS, Morsy, TA, 1976: Myiasis in Medicolegal practice. J. Egypt. Soc. Parasitol. 6:71-76.

Steyskal, G, El-Bialy, S, 1967: A List of Egyptian Diptera with a Bibliography and Key to Families. Tech. Bull. No. 3; Agriculture Ministry.

Sukontason, KL, Sanit, S, Klong-Klaew, T, Tomberlin, JK, Sukontason, K, 2014: Sarcophaga (Liosarcophaga) dux (Diptera: Sarcophagidae): A flesh fly species of medical importance. Biol. Res. 47, 1:14-20.

Szakacs, TA, MacPherson, P, Sinclair, BJ, GiIl, BD, McCarthy, AE, 2007: Nosocomial myiasis in a Canadian intensive care unit. CMAJ. 177, 7:719-20.

Tantawi, TI, Greenberg, B, 1993: The effect of killing and preservative solutions on estimates of maggot age in forensic cases. J. Forensic Sci. 38, 3:702-7.

Tantawi, TI, Williams, KA, Villet, MH, 2010: An accidental but safe and effective use of $\mathrm{Lu}$ cilia cuprina (Diptera: Calliphoridae) in maggot debridement therapy in Alexandria, Egypt. J. Med. Entomol. 47, 3:491-4.

Terra, D, de Siqueira, JT, 1980: Intra-oral myiasis. Quintessenc.7, 8:11-4.

Verettas, DA, Chatzipapas, CN, Drosos, GI, Xarchas, KC, Staikos, C, 2008: A maggot infestation (myiasis) of external fixation pin sites in diabetic patients. Trans. R. Soc. Trop. Med. Hyg. 102, 9:950-2.

William, B, 1931: The treatment of chronic osteomyelitis with the maggot (larva of the blow fly). J. Bone Joint Surg. 13:438-75.

Zaglool, DA, Tayeb, K, Khodari, YA, Farooq, MU, 2013: First case report of human myiasis with Sarcophaga species in Makkah city in the wound of a diabetic patient. J. Nat. Sci. Biol. Med. 4, 1:225-8.

Zayed, AA, 1992: Studies on Rhinoestrus purpureus (Diptera: Oestridae) larvae infesting donkeys (Equus asinus) in Egypt. III. Pupal duration under controlled conditions. Vet. Parasitol. 44, 3/4:285-90.

Zumpt, F, 1965: Myiasis in Man and Animals in the Old World. Butterworth and Co. Ltd. 